\title{
The Main Central Thrust Revisited: New Insights from Sikkim Himalaya
}

\author{
Sudipta Neogi ${ }^{*}$ and $V$ Ravikant ${ }^{2}$ \\ 1 Geological Survey of India, 27 J.L. Nehru Road, Kolkata - 700 016, INDIA \\ 2 Indian Institute of Technology, Roorkee-247667, INDIA \\ * For correspondence, email: sudiptaneogi@hotmail.com
}

One of the most coherent crustal sections in the entire Himalaya, from the point of view of lack of disruption or repetitions of key beds due to thrusting, is exposed in Sikkim. Structural studies across this unique section in Sikkim, covering the so-called Lesser Himalaya, the Higher Himalaya and the intervening Main Central
Thrust zone (MCT zone) reveals a remarkable continuity in structures and metamorphic history. Due to lack of clear evidences for pervasive ductile shearing and thrusting, the position of the MCT in Sikkim and therefore, the exact demarcation of the Lesser and Higher Himalayan Belts has remained controversial with the

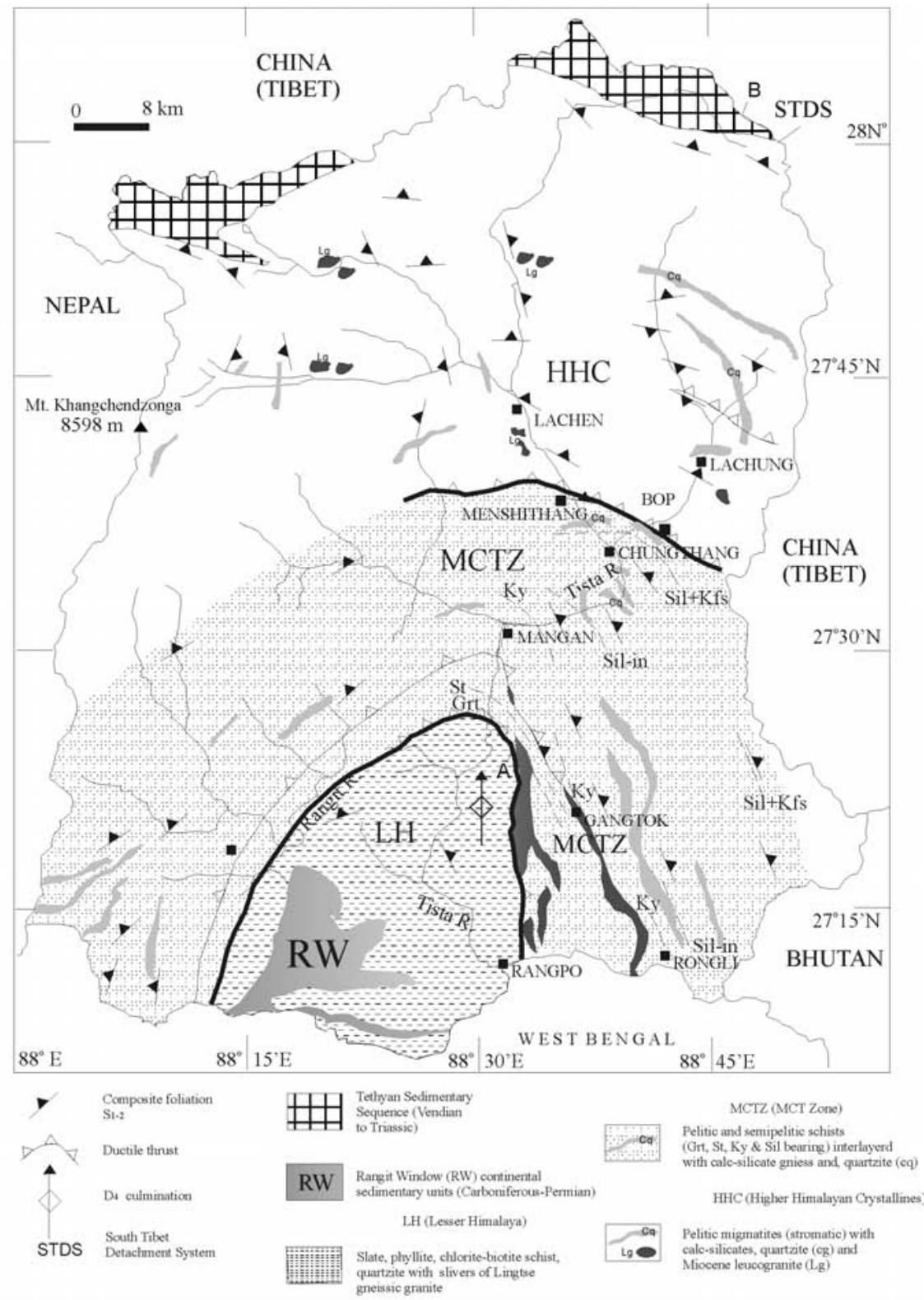


MCT being placed at different positions by various workers.

Rocks from the entire studied section in Sikkim preserve imprints of four deformational episodes (D1-D4), with broad similarity in their deformation patterns and structural elements. A single penetrative regional planar structure (S2), associated with F2 folds and sub-parallel to narrow ductile shears, formed during the dominant D2 deformation episode. A complete and systematic sequence of inverted progressive Barrovian metamorphic zones is exposed, showing a regular pattern of variation of $\mathrm{P}$ and $\mathrm{T}$ (increasing $\mathrm{P}$ and T upsection; Neogi et al. 1998, Dasgupta et al. 2004). Metamorphism was broadly coeval with the progressive deformation that produced the regional pervasive S2 fabric in all the domains, and continuing into the D2-D3 interkinematic period. The consistent relation of the porphyroblastic phases with the marker fabric in all the domains suggests a common growth history for the "index minerals" defining the Barrovian metamorphic zones.

In Sikkim, it has not been possible to map the MCT following its original definition as a thrust fault or as a lithostratigraphic boundary between the two distinct geological units, Lesser and Higher Himalaya, based on structural criteria. What is now seen is a broad zone of distributed ductile shearing with few localised discrete zones of ductile deformation, which have accommodated a major part of the shearing strain (Figure 1). This comes closest to the definition of the MCT zone, as identified from other parts of the Himalaya. The confusion in the definition of the MCT as a significant lithostratigraphic boundary between the Lesser and Higher Himalaya and the $\sim 15-25 \mathrm{~km}$ wide MCT zone as observed now, can be largely reconciled if it is considered that these two had formed separately in time. We do not rule out the possibility that the lithostratigraphic boundary may be a relatively older surface that has been largely modified by a wide ductile shear zone during the main phase of Himalayan shortening. This is consistent with the work of DeCelles et al. (2000), Robinson et al. (2001) and Gehrels et al. (2003), who suggested that the Higher Himalaya may represent an exotic terrane that was accreted to the Indian margin at some time during the Palaeozoic. Without discounting the possibility that parallel fabrics in the Lesser Himalaya, MCT zone and Higher Himalaya could be time-transgressive and in spite of the fact that direct correlation of the deformation events in these domains is not possible based on structural data alone, the simplest explanation seems to be that at least a part of the deformation and metamorphic history experienced by these domains was common and that the inverted metamorphic sequence was established during a single tectonothermal episode. This is consistent with the observed structural integrity, coupled with a smooth P-T profile of increasing $\mathrm{P}$ and $\mathrm{T}$ upsection, established through rigorous themobarometry in earlier studies in Sikkim. Available age data from included monazite are not in conflict with such an interpretation and do not rule out a common event affecting the entire section.

A workable model on the Himalayan inverted metamorphic sequence would have to account for mechanisms in terms of combinations of heat sources and tectonic processes by which mineral growth could occur syntectonically with the second deformation event in each domain but at different times and in addition yield a profile which shows smooth increase in both $\mathrm{P}$ and $\mathrm{T}$ with structural height. The results of the present studies are evaluated in the light of available monazite age data.

\section{References}

Dasgupta S, J Ganguly, and S Neogi. 2004. Journal of Metamorphic Geology 22: $395-412$

DeCelles, P.G., Gehrels, G.E., Quade, J., Lareau, B., and Spurlin, M., 2000. Science 288, 497-499

Gehrels, G.E., DeCelles, P.G., Martin, A., Ohja, T.P., Pinhassi, G. and Upreti, B.N. 2003. Geological Society of America Today 13 (9): 4-9

Neogi, S., Dasgupta, S., Fukuoka, M., 1998. Journal of Petrology 39: 61-99

Robinson, D.M., DeCelles, P.G., Patchett, P.J., Garzione, C.N., 2001. Earth and Planetary Science Letters 192: 507-521 